\title{
PD-L1 expression as predictive biomarker in patients with NSCLC: a pooled analysis
}

\author{
Francesco Passiglia ${ }^{1, *}$, Giuseppe Bronte ${ }^{1, *}$, Viviana Bazan ${ }^{1, *}$, Clara Natoli $^{2}$, Sergio \\ Rizzo $^{1}$, Antonio Galvano ${ }^{1}$, Angela Listì ${ }^{1}$, Giuseppe Cicero ${ }^{1}$, Christian Rolfo ${ }^{3}$, Daniele \\ Santini ${ }^{4}$, Antonio Russo ${ }^{1}$ \\ ${ }^{1}$ Section of Medical Oncology, Department of Surgical, Oncological and Oral Sciences, University of Palermo, Palermo, Italy \\ ${ }^{2}$ Department of Medical, Oral and Biotechnological Sciences, University "G. D’Annunzio", Chieti, Italy \\ ${ }^{3}$ Phase I- Early Clinical Trials Unit, Oncology Department and Multidisciplinary Oncology Center Antwerp (MOCA), Antwerp \\ University Hospital, Edegem, Belgium \\ ${ }^{4}$ Medical Oncology Department, Campus Biomedico, University of Rome, Rome, Italy \\ *These authors have contributed equally to this work \\ Correspondence to: Antonio Russo, e-mail: antonio.russo@usa.net \\ Keywords: PD-L1, predictive biomarker, immunotherapy, anti-PD 1/PD-L1 MoAbs, NSCLC \\ Received: December 03, $2015 \quad$ Accepted: February 11, $2016 \quad$ Published: February 22, 2016
}

\section{ABSTRACT}

Background: Clinical trials of immune checkpoints modulators, including both programmed cell death-1 (PD-1) and programmed cell death-ligand 1 (PD-L1) inhibitors, have recently shown promising activity and tolerable toxicity in pre-treated NSCLC patients. However the predictive role of PD-L1 expression is still controversial. This pooled analysis aims to clarify the association of clinical objective responses to anti PD-1/PD-L1 monoclonal antibodies (MoAbs) and tumor PD-L1 expression in pre-treated NSCLC patients.

Methods: Data from published studies, that evaluated efficacy and safety of PD-1/ PD-L1 inhibitors in pre-treated NSCLC patients, stratified by tumor PD-L1 expression status (immunohistochemistry, cut-off point $1 \%$ ), were collected by searching in PubMed, Cochrane Library, American Society of Clinical Oncology, European Society of Medical Oncology and World Conference of Lung Cancer, meeting proceedings. Pooled Odds ratio (OR) and $95 \%$ confidence intervals ( $95 \% \mathrm{CIs}$ ) were calculated for the Overall Response Rate (ORR) (as evaluated by Response Evaluation Criteria in Solid Tumors, version 1.1), according to PD-L1 expression status.

Results: A total of seven studies, with 914 patients, were eligible. Pooled analysis showed that patients with PD-L1 positive tumors (PD-L1 tumor cell staining $\geq 1 \%$ ), had a significantly higher ORR, compared to patients with PD-L1 negative tumors (OR: 2.44; 95\% CIs: 1.61-3.68).

Conclusions: PD-L1 tumor over-expression seems to be associated with higher clinical activity of anti PD-1/PD-L1 MoAbs, in pre-treated NSCLC patients, suggesting a potential role of PD-L1 expression, IHC cut-off point $1 \%$, as predictive biomarker for the selection of patients to treat with immune-checkpoint inhibitors.

\section{INTRODUCTION}

Cancer immunotherapy is emerging as a very promising therapeutic strategy for several solid tumors, including non-small cell lung cancer (NSCLC). Differently from other treatment approaches directed against the tumor, such as chemotherapy or targeted therapy [1-6], targeting the immune system offers the potential for durable activity and long-term survival outcomes, regardless of tumor's histological subtype or mutation status, with a unique, tolerable, toxicity profile. Among the different immunotherapeutic strategies under clinical investigation in NSCLC, the blockade of inhibitory immune-checkpoints with monoclonal 
antibodies (MoAbs), is currently considered the most promising approach, promoting the immune-response against cancer cells [7-9]. Programmed cell death protein-1 (PD-1) is a checkpoint receptor expressed on the surface of activated T-cells, as well as on B-cells and natural killers (NK) [10], binding its natural ligands, PD-L1 and PD-L2, which may be expressed by both stromal and tumor cells [11]. The PD-1/PD-L1 axis is an inhibitory signaling pathway, causing T-cells exhaustion and inactivation, to prevent autoimmune response [1113]. However it represents also an important mechanism of immune-escape, co-opted by the tumor cells to limit T-cells activity in the tumor microenvironment during the late-stage of the "immune-editing process" [14]. An improved understanding of cancer immunology has led to the development of several MoAbs which are able to revert a non-efficient or suppressed immune-response by the blockade of the PD-1/PD-L1 axis $[15,16]$. There are two different classes of MoAbs: the anti-PD-1 MoAbs, Nivolumab and Pembrolizumab are fully human and humanized, respectively, IgG4 MoAbs, blocking the binding between PD-1 receptor and its natural ligands, PD-L1 and PD-L2; the anti-PD-L1 MoAbs Atezolizumab, Durvalumab, and Avelumab are IgG1 isotypes with genetically modified Fc fragments, which block the PD-L1 and prevent its interaction with PD-1 receptor $[17,18]$. All these MoAbs have shown a very promising activity in early phase I trials, reaching an overall response rates (ORR) of about $20 \%$, in a heavily pre-treated and unselected NSCLC population [19-22]. Most of such responses occur relatively early, about 50\% within eight weeks of treatment, and may be maintained for a long time [19]. These encouraging data have been recently confirmed by two prospective, randomized, phase III trials, comparing Nivolumab vs Docetaxel, in both squamous and non-squamous, advanced NSCLC, after prior chemotherapy-regimens failure [23, 24]. Even more exciting was the overall survival (OS) benefit obtained with Nivolumab in this setting of patients, leading to the approval of the first anti-PD-1 MoAb, by the Food and Drug Administration (FDA), for the secondline treatment of squamous NSCLC. A relationship between PD-L1 expression on tumor cells and ORR has been first suggested by the phase I study of Topalian et al. [25]. In such study among 42 patients with different solid tumors evaluated with immunohistochemical analysis, none of those with PD-L1 negative tumor obtained an ORR, while about one third of patients with PD-L1 positive tumors had a clinical response. Since then, almost all clinical studies of immune-checkpoint inhibitors in NSCLC investigated the potential correlation between tumor PD-L1 expression and antiPD-1/PD-L1 MoAbs activity/efficacy [19-24, 26-30], in order to validate PD-L1 expression as predictive biomarker. The majority of such studies have shown that PD-L1 over-expression is associated with significantly higher ORR in pre-treated NSCLC population [19, 20, 22, 24, 27-29], while some other studies have not found a significant association $[21,23,26]$. Although different immunohistochemistry (IHC) cut-off points, ranging from $1 \%$ to $50 \%$, have been used to define the PD-L1 positivity in tumor specimens, the results of the phase III CheckMate 057 study [24] have recently shown that PD-L1 (IHC, cut-off point 1\%) significantly correlated with ORR, progression free survival (PFS) and overall survival (OS), in pre-treated NSCLC patients. These data suggested PD-L1 at the lowest expression level (IHC, cut-off point 1\%) as the best cut-off, allowing to include all patients who may really benefit from these therapies. The aim of this pooled-analysis is to combine and analyze simultaneously all the studies reporting the ORR of pre-treated NSCLC patients receiving anti PD1/PD-L MoAbs, stratified according to the PD-L1 expression status (IHC, cut-off point $1 \%$ ), in order to provide a more precise estimation of the predictive role of PD-L1 expression in NSCLC.

\section{RESULTS}

Our search, according to the aforementioned criteria, performed in October 2015, identified 211 publications. Among these, after a careful selection procedure, only seven studies (914 patients) met our inclusion criteria and were included in the pooledanalysis (Figure 1) [20, 21, 23, 24, 26, 27, 30]. Three of these were early phase I studies, reporting the updated results of the immune-checkpoint inhibitors, Pembrolizumab [20], Atezolizumab [21], and Avelumab activity [30], in pre-treated NSCLC patient cohorts. In particular, the KEYNOTE-001 was a modern, large phase I study, including about 500 NSCLC patients treated with Pembrolizumab, which has shown an ORR of about $20 \%$ and an OS of about 12 months in the overall population, even higher among the patients with an increased tumor PD-L1 expression [20]. Two were phase II studies: a single arm trial of Nivolumab in patients with advanced refractory squamous NSCLC [26], and the randomized phase II trial comparing Atezolizumab vs docetaxel in 287 pre-treated NSCLC patients, whose interim results have recently shown a significant benefit in favour of Atezolizumab, correlating with an increasing tumor PDL1 expression [27]. Two randomized, phase III studies, comparing Nivolumab vs docetaxel, in pre-treated, both squamous [23] and non-squamous [24] NSCLC patients, have both shown a significant improvement of the ORR and $\mathrm{OS}$ in the overall population treated with Nivolumab, reporting opposite results in the PD-L1 expression analysis. Indeed, the CheckMate 057 study demonstrated a strong predictive value of tumor PD-L1 expression in non-squamous NSCLC [24], while no significant association between Nivolumab benefit and PD-L1 expression has been found in patients with squamous 
histology in the CheckMate 017 trial [23]. In the included studies, sample sizes of the analyzed population ranged from 53 [21] to 231 [24], while the percentage of PDL1 positive tumors, IHC cut-off point $1 \%$, ranged from $50 \%$ [21] to $85 \%$ [20]. All these studies analyzed the ORR of pre-treated NSCLC patients stratified by tumor PD-L1 expression status (immunohistochemistry, cut-off

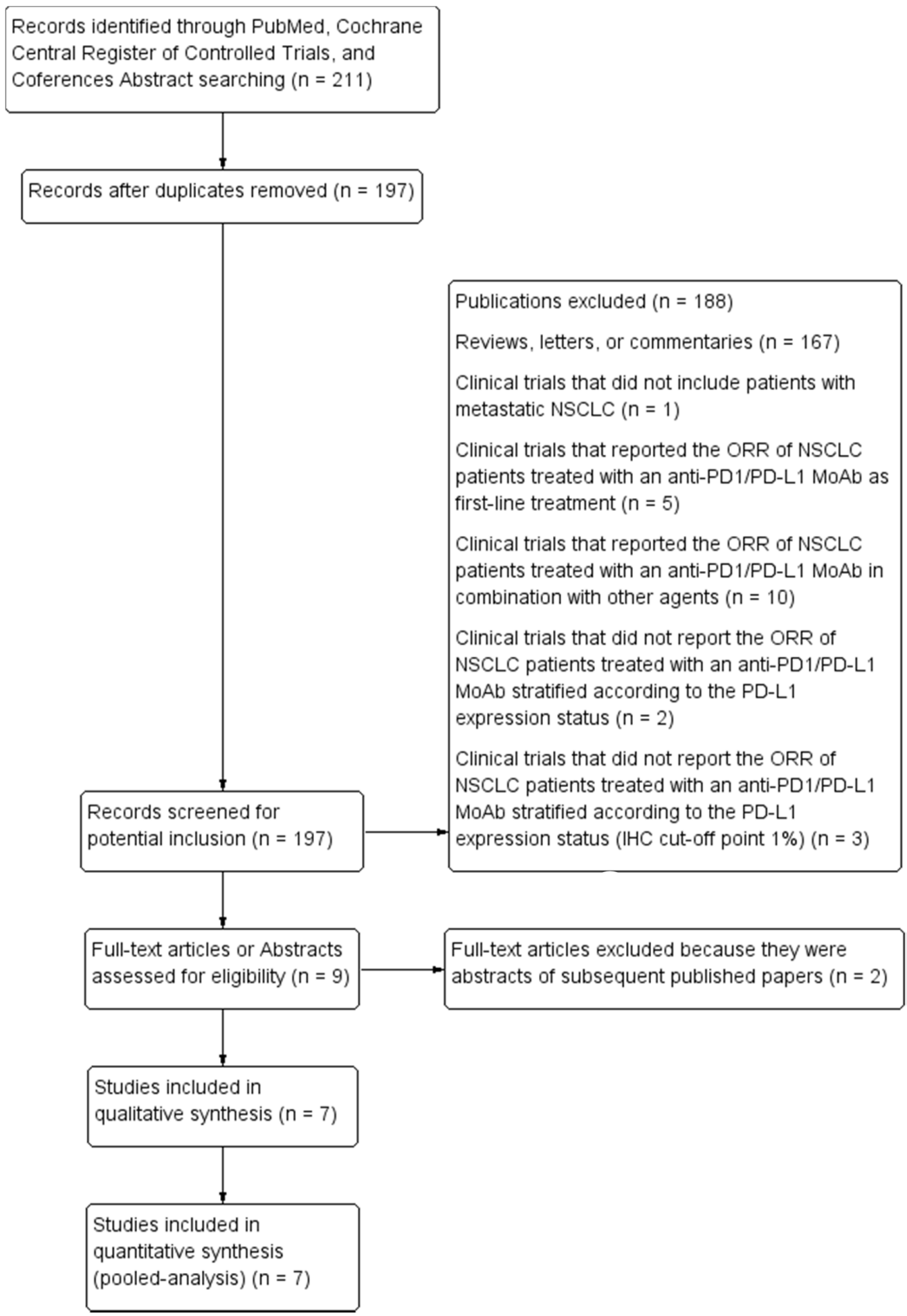

metastatic NSCLC $(n=1)$

Cinical trials that reported the ORR of NSCLC patients treated with an anti-PD1/PD-L1 MoAb as

Clinical trials that did not report the ORR of NSCLC patients treated with an anti-PD1/PD-L1

to the PD-L

Clinical trials that did not report the ORR of NSCLC patients treated with an anti-PD1/PD-L1

PD-L1

Records screened for

on $(n=197)$ point $1 \%$ ). A detailed description of the selected studies is reported in the Table 1.

Pooled analysis showed that patients with PD-L1 positive tumors (PD-L1 tumor cell staining $\geq 1 \%$ ) had a significantly higher ORR compared to patients with PD-L1 negative tumors (OR: 2.44; 95\% CIs: 1.61-3.68) (Figure 2). A significant difference in activity by PD-L1 
Table 1: Characteristics of the trials included in the pooled-analysis

\begin{tabular}{|c|c|c|c|c|c|c|c|c|}
\hline $\begin{array}{l}\text { Study } \\
\text { (reference) }\end{array}$ & Drug & $\begin{array}{l}\text { Detection } \\
\text { (cut-point) }\end{array}$ & $\begin{array}{c}\text { ORR } \\
(\text { PD-L1+) } \\
\text { n.*(\%) }\end{array}$ & $\begin{array}{c}\text { ORR } \\
\text { (PD-L1-) } \\
\text { n.*(\%) }\end{array}$ & $\begin{array}{l}\text { PFS (PD- } \\
\text { L1+) m. } \\
(95 \% \text { CI) }\end{array}$ & $\begin{array}{l}\text { PFS (PD- } \\
\text { L1-) m. } \\
(95 \% \text { CI) }\end{array}$ & $\begin{array}{l}\text { OS (PD- } \\
\text { L1+) m. } \\
(95 \% \mathrm{CI})\end{array}$ & $\begin{array}{c}\text { OS (PD- } \\
\text { L1-) m. } \\
(95 \% \mathrm{CI})\end{array}$ \\
\hline $\begin{array}{l}\text { Rizvi et al. } \\
2015 \text { (phase II) } \\
(26)\end{array}$ & Nivolumab & IHC (1\%) & $9 / 45(20)$ & 4/31 (13) & N.A & N.A & N.A & N.A \\
\hline $\begin{array}{l}\text { Brahmer et al. } \\
2015 \text { (phase } \\
\text { III) (23) }\end{array}$ & Nivolumab & IHC (1\%) & $11 / 63(17)$ & $9 / 54(17)$ & 3.3 & 3.1 & 9.3 & 8.7 \\
\hline $\begin{array}{l}\text { Borghaei et al. } \\
2015 \text { (phase } \\
\text { III) (24) }\end{array}$ & Nivolumab & IHC (1\%) & $38 / 123(31)$ & $10 / 108(9)$ & 4.2 & 2.1 & 17.2 & 9.4 \\
\hline $\begin{array}{l}\text { Garon et al. } \\
2015 \text { (phase I) } \\
(20)\end{array}$ & Pembrolizumab & IHC (1\%) & $37 / 134(27)$ & $2 / 22(9)$ & N.A & N.A & N.A & N.A \\
\hline $\begin{array}{l}\text { Rizvi et al. } \\
2014 \text { (phase I) } \\
(21)\end{array}$ & Atezolizumab & IHC (1\%) & $8 / 26(31)$ & $5 / 26(20)$ & N.A & N.A & N.A & N.A \\
\hline $\begin{array}{l}\text { Spira et al. } \\
2015 \text { (phase II) } \\
(27)\end{array}$ & Atezolizumab & IHC (1\%) & 17/93 (18) & $4 / 51(8)$ & 3.3 & 1.9 & N.A & N.A \\
\hline $\begin{array}{l}\text { Gulley et al. } \\
2015 \text { (phase I) } \\
(30)\end{array}$ & Avelumab & IHC (1\%) & $17 / 118(14)$ & $2 / 20(10)$ & 3 & 1.4 & N.A & N.A \\
\hline
\end{tabular}

ORR, Overall Response Rate; PD-L1; Programmed death-ligand 1; IHC, immunohistochemistry; n., number; m., months; N.A, not available.

*The number of patients reported corresponds to the number of patients evaluable

status was confirmed for anti-PD1 MoAbs (OR: 2.62; 95\% CIs: 1.60-4.28) (Figure 3), with a no significant trend for anti-PD-L1 MoAbs (OR: 2.07; 95\% CIs: 0.984.38) (Figure 4). The pooled OR for ORR was calculated using fixed-effect model, because of non-significant heterogeneity between treatment effects (Q-test: P: 0.38). Publication bias have not been found either by Begg's and Egger's tests for ORR (P: 0.5 and P: 0.27, respectively), according to the PD-L1 expression status (Figure 5).

\section{DISCUSSION}

This pooled analysis included seven studies which evaluated the ORR of patients with NSCLC treated with anti PD1/PD-L1 MoAbs who received prior chemotherapy regimens stratified according to the tumor PD-L1 expression status (IHC, cut-off point 1\%). The results of this work have shown that tumor PD-L1 positivity (PD-L1 tumor cell staining $\geq 1 \%$ ) is associated with significantly higher ORR, suggesting a potential role of tumor PD-L1 over-expression as predictive biomarker for clinical setting. After the recent approval of Nivolumab by FDA for the second-line treatment of squamous NSCLC, searching for predictive biomarkers has become an urgent issue for clinical research. A validated biomarker would allow to select those patients who could benefit more from immune-therapies, sparing the others from ineffective high-cost treatments, as well as futile immune-related toxicities. In this scenario, tumor PDL1 expression represents the predictive biomarker most evaluated in clinical studies. Although the majority of such studies suggested a significant association between tumor PD-L1 expression and anti-PD-1/PD-L1 MoAbs activity $[20,24,27]$, the two largest phase III randomized CheckMate 017 and 057 trials have shown opposite results. Indeed the CheckMate 017 study of Nivolumab in squamous NSCLC did not report any difference in terms of efficacy according to the tumor PD-L1 expression status [23], whereas the CheckMate 057 has recently shown that ORR nearly tripled and median OS nearly doubled with Nivolumab vs Docetaxel in pre-treated patients with PD-L1 positive non-squamous NSCLC [24]. Such data suggested that PD-L1 has a predictive value limited to the adenocarcinoma, likely influencing also the results of our analysis. An individual patients data analysis by histology would be useful to determine if the predictive role of PD-L1 expression in NSCLC is histology-driven, but unfortunately 
we didn't have such informations. Another major issue emerging from the studies regards the heterogeneity of the IHC cut-offs, ranging from $>1 \%$ to $>50 \%$, used to define the PD-L1 positivity in tumor specimens. Indeed PD-L1 has shown to be predictive of Nivolumab activity at different cut offs of $1 \%, 5 \%$ and $10 \%$ [24], while in the more recent KEYNOTE-001 trial of pembrolizumab in advanced NSCLC, patients' survival significantly differed between patients with PD-L1 expression $>50 \%$ in comparison with patients with a PD-L1 $<50 \%$ [20]. The multitude of the detection methods by different PD-L1 IHC MoAbs used in the included studies, has further complicated the interpretation of the biomarker data analysis as well as their clinical applicability. The International Association for the Study of Lung Cancer (IASLC) Pathology Committee is currently working on this field in order to standardize and validate a reproducible IHC test for PD-L1 assessment [31]. According to the CheckMate 057 results [24], our work also demonstrated that tumor PD-L1 expression at the lowest IHC cut-off of $1 \%$, significantly correlated with anti-PD-1/

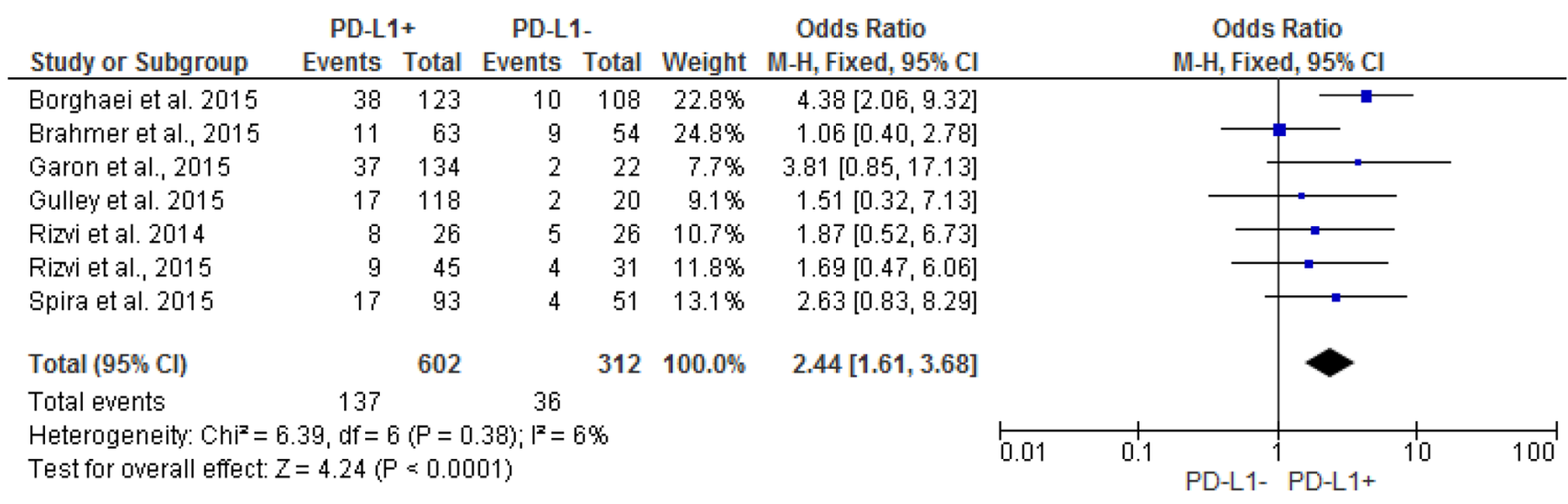

Figure 2: Forest plot showing odds ratio for overall response rate to anti-PD-1/PD-L1 monoclonal antibodies according to the tumor PD-L1 expression status, in pre-treated NSCLC patients.

\begin{tabular}{|c|c|c|c|c|c|c|c|c|c|c|}
\hline Study or Subgroup & $\begin{array}{l}\text { PD-L1 } \\
\text { Events }\end{array}$ & Total & $\begin{array}{l}\text { PD-L' } \\
\text { Events }\end{array}$ & Total & Weight & $\begin{array}{c}\text { Odds Ratio } \\
\text { M-H, Fixed, } 95 \% \mathrm{Cl}\end{array}$ & \multicolumn{4}{|c|}{$\begin{array}{c}\text { Odds Ratio } \\
\text { M-H, Fixed, } 95 \% \mathrm{Cl}\end{array}$} \\
\hline Borghaei et al. 2015 & 38 & 123 & 10 & 108 & $34.0 \%$ & $4.38[2.06,9.32]$ & & & & \\
\hline Brahmer et al., 2015 & 11 & 63 & 9 & 54 & $37.0 \%$ & $1.06[0.40,2.78]$ & & & & \\
\hline Garon et al., 2015 & 37 & 134 & 2 & 22 & $11.5 \%$ & $3.81[0.85,17.13]$ & & & & \\
\hline Rirvi et al., 2015 & 9 & 45 & 4 & 31 & $17.5 \%$ & $1.69[0.47,6.06]$ & & & & \\
\hline Total $(95 \% \mathrm{Cl})$ & & 365 & & 215 & $100.0 \%$ & $2.62[1.60,4.28]$ & & & & \\
\hline Total ewents & 95 & & 25 & & & & & & & \\
\hline $\begin{array}{l}\text { Heterogeneity: Chi = } \\
\text { Test for overall effect: }\end{array}$ & $\begin{array}{l}35, \mathrm{df}=3 \\
=3.82 \mathrm{G}\end{array}$ & $\begin{array}{l}(P= \\
=0.0\end{array}$ & $\begin{array}{l}12) ;\left.\right|^{2}= \\
101)\end{array}$ & $9 \%$ & & & 0.01 & 0.1 & PD-L1+ 10 & 100 \\
\hline
\end{tabular}

Figure 3: Forest plot showing odds ratio for overall response rate to anti-PD-1 monoclonal antibodies according to the tumor PD-L1 expression status, in pre-treated NSCLC patients.

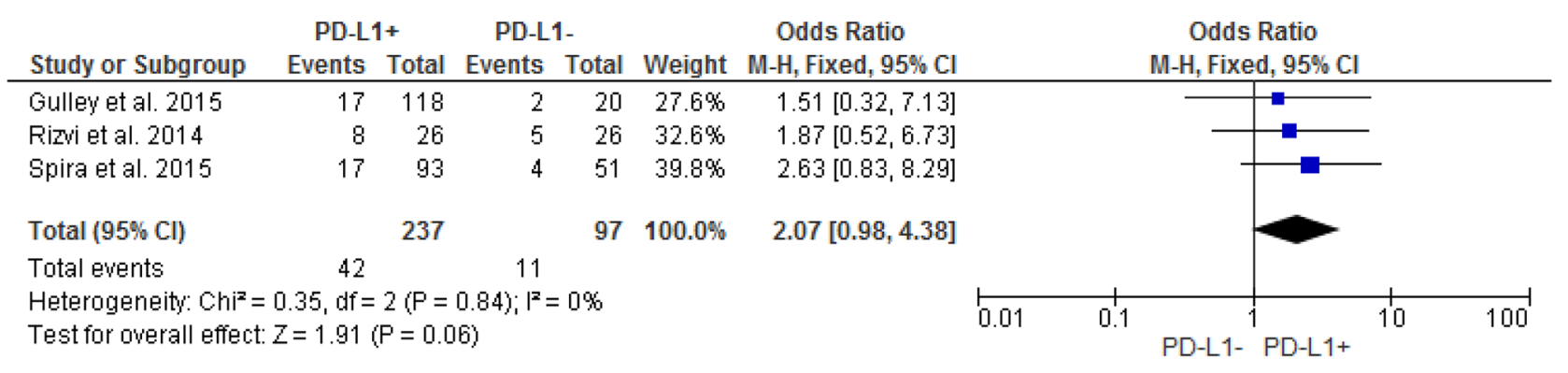

Figure 4: Forest plot showing odds ratio for overall response rate to anti-PD-L1 monoclonal antibodies according to the tumor PD-L1 expression status, in pre-treated NSCLC patients. 
PD-L1 MoAbs activity in pre-treated NSCLC patients, confirming its potential role as predictive biomarker for clinical use. The non-significant trend observed for antiPD-L1 MoAbs is likely due to the lower number of patients included in the subgroup analysis. Similarly to other studies our work also demonstrated that more than $10 \%$ of PD-L1 negative patients received also benefit by anti PD-1/ PD-L1 therapies, suggesting that tumor PD-L1 expression could not be able to predict the overall immunotherapy benefit in NSCLC $[32,33]$. Of course, the ORR (WHO, RECIST) may not be considered as the best endpoint to assess the predictive value of tumor PD-L1 expression. Differently from oncogene drivers, such as EGFR and EML4-ALK, which are associated with high response rates to targeted therapies (1-4), the predictive power of tumor PD-L1 expression should be evaluated on the basis of long-term survival outcomes associated with these treatments. To date most of such outcomes are still immature, although preliminary OS for some of the anti-PD1/PD-L1 inhibitors seems to be associated with tumor PD-L1 status [20, 24]. A retrospective analysis presented at the last WCLC has shown that patients with NSCLC who achieved a best response (CR or PR) in the single arm study (CA209063) of Nivolumab had the longest survival, suggesting the ORR as a reliable surrogate endpoint of OS in patients receiving immunotherapy [34]. In addition patients whose best response was SD or PD according to RECIST and continued Nivolumab beyond PD had longer survival compared to patients with no treatment beyond PD [34]. Such findings suggested that traditional response criteria may not be able to fully capture the immune-therapy activity. Because of the retrospective nature of this analysis, such results should be interpreted cautiously and need to be confirmed by prospective studies. The immune-related response criteria (ir-RC) have shown to be more appropriate to capture the novel response patterns observed with immunotherapeutic agents and should be included in clinical trials investigating immunotherapies. Indeed according to the ir-RC the appearance of new lesions doesn't necessarily identify a $\mathrm{PD}$, because responses may occur also after a long time and/ or a conventional "RECIST" PD [35]. Another limitation of our analysis is represented by the heterogeneity of the selected studies, including four phase I-II single arm studies $[20,21,26,30]$ and three randomized phase II-III clinical trials [23, 24, 27], which investigated different anti-PD1/ PD-L1 MoAbs. However, all these MoAbs act on the same immune-modulating pathway, but especially the same study population. Indeed only studies reporting data dedicated to pre-treated NSCLC patients were included, in order to enhance the precision and the accuracy of the results.

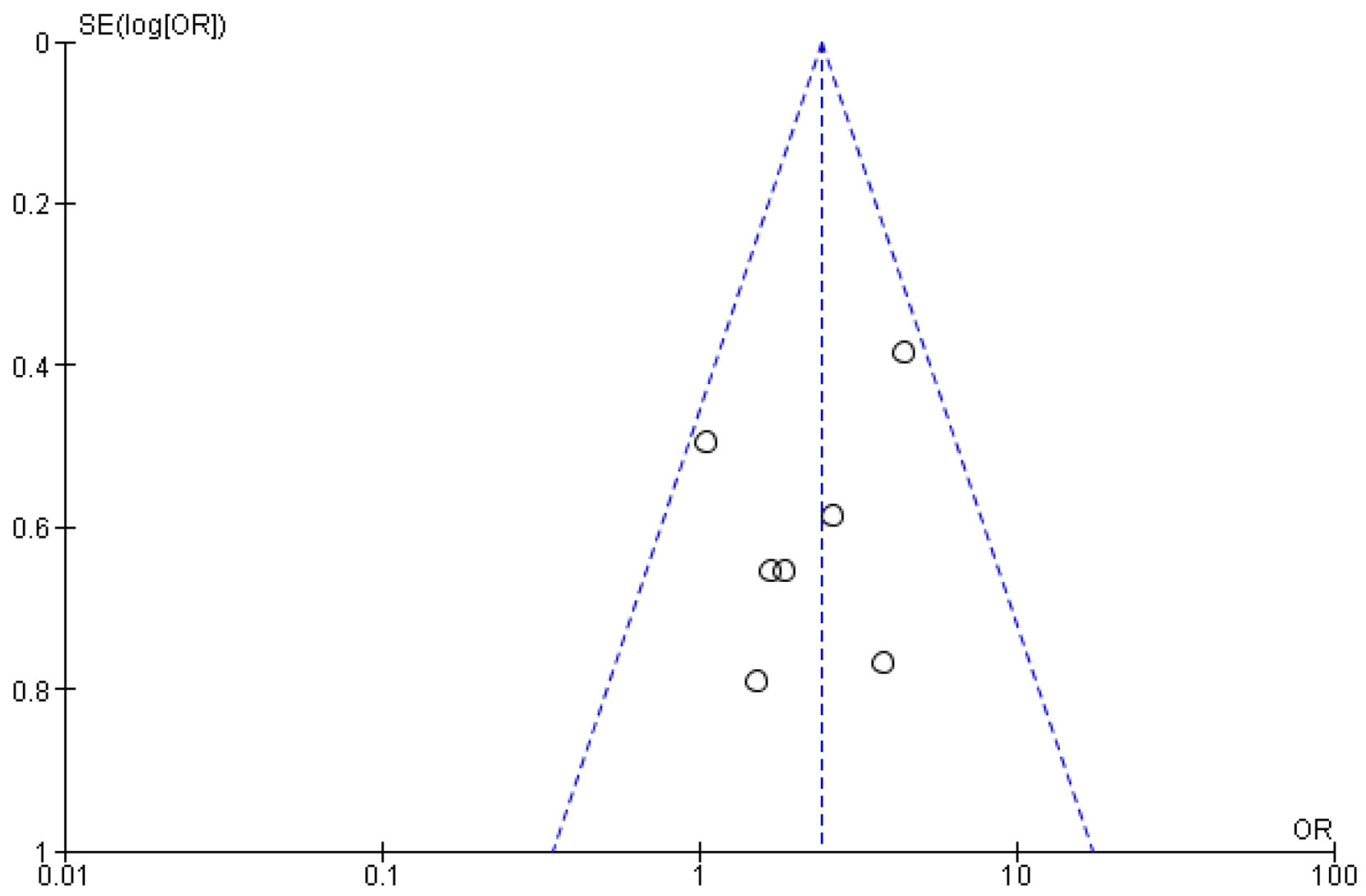

Figure 5: Funnel plot of odds ratio (OR) for response rate (RR) according to the PD-L1 expression status in pre-treated NSCLC patients receiving anti-PD-1/PD-L1 treatments. Each study is represented by one circle- the vertical line represents the pooled effect estimate. 
Finally the high PD-L1 expression heterogeneity in the tumor microenvironment could further reduce the potential role applicability of such predictive biomarker for clinical setting [36]. Indeed PD-L1 expression seems to be a dynamic biomarker, subjected to both space (primary vs metastatic lesions) and time (interval between biopsy and subsequent treatments)-dependent variability [37]. A biopsy sample is just a snapshot of the tumor not reflecting the overall tumor microenvironment. A recent study has shown a low intra-patient heterogeneity and temporal changes in PD-L1 expression using paired synchronous and metachronous tumor specimens of 39 NSCLC patients treated at Memorial Sloan Kettering Cancer Center [38] supporting the reliability of such biomarker for clinical use. In addition to such technical issue, some biological aspects related to the PD-L1 expression need to be also pointed out. Recent evidences suggested two different pathways modulating the PD-L1 expression on the tumor cell surface: the "inflammation-driven", INF-gamma-mediated, PD-L1 expression, which is localized at sites of inflammation and is usually associated with a baseline tumor T-cell infiltration; and the "oncogene-driven", PD-L1 expression, which is constitutive, not increased by the inflammation process and associated with neither an immune response nor a T-cell tumor infiltration $[39,40]$. Since several studies showed a significant correlation between a baseline T-cell infiltration in the tumor microenvironment and the clinical responses to immune-checkpoint inhibitors [41-43], it may be hypothesized that the first group of tumors, with an inflamed tumor microenvironment, will benefit more from anti-PD-1/ PD-L1 directed therapies, compared to those with an oncogene-driven PD-L1 expression status, in absence of T-cell infiltration in the tumor microenvironment. The search for predictive biomarkers needs to be implemented by the identification of other pathological or genomic determinants of response to these therapies. Some studies have recently demonstrated that tumor infiltrating immune cell IHC PD-L1 expression predict responses to Atezolizumab stronger than tumor PD-L1 expression [44], and that combining both tumor-infiltrating lymphocytes and IHC PD-L1 expression status, allow to identify four different subgroup of tumor microenvironment, which could benefit from different treatment strategies, including combination therapies [45]. Another work has shown that an elevated non-synonymous mutation burden, including DNA repair mutations, a molecular smoking signature, and a high neo-antigen load, are strongly associated with clinical activity of Pembrolizumab in NSCLC patients [46]. Some correlations between tumor mutation burden and PD-L1 expression have been also found, even if it needs to be better explored in larger prospective studies.

Despite several limitations our pooled-analysis shows that tumor PD-L1 expression, IHC cut-off $>1 \%$, is associated with significantly higher ORRs to anti PD-1/ PD-L1 MoAbs, in pre-treated NSCLC patients. These data suggest that PD-L1 at the lowest expression level, though still limited by varied testing approaches and definitions of positivity, has a potential role as predictive biomarker for clinical setting. Probably, as suggested by recent studies, a combination of tumor PD-L1 expression with other "immune-biomarkers" will enhance our ability to identify not only the best candidate to receive immune-therapies, but also the mechanisms of immune-evasion at a single patient level, and ultimately personalize the immunetreatments and combination strategies.

\section{MATERIALS AND METHODS}

\section{Search for clinical trials}

We performed our pooled-analysis according to a predefined written protocol. We searched for all published studies, that report the ORR of patients with NSCLC treated with anti PD1/PD-L1 MoAbs, who received prior chemotherapy regimens, stratified by tumor PD-L1 expression status (IHC cut-off point 1\%). Publications were identified by an electronic search in Medline, using PubMed online service, updated in October 2015. The search for publications was made by other databases including the Cochrane Library and EMBASE. However the search on PubMed allowed the widest collection of publications about this topic. The following search terms were used: "PD-1", "PD-L1", "lung cancer", "NSCLC", "non-small cell lung cancer", "predictive biomarker", "anti-PD1", "anti-PD-L1", "monoclonal antibodies", "cancer immunotherapy". The search was limited to human studies in the English language. The results were supplemented with manual searches of American Society of Clinical Oncology (ASCO), European Society of Medical Oncology (ESMO), and World Conference of Lung Cancer (WCLC), meeting proceedings, references of selected articles and published reviews. A systematic review on this topic in the Cochrane database of systematic reviews was not found.

\section{Selection criteria}

According to this search clinical trials were taken into account if they had to fulfil all the following inclusion criteria: 1) only patients with metastatic NSCLC were included; 2) only patients who received prior therapies were included 3) studies that report the ORR of NSCLC patients treated with an anti-PD1/PDL1 MoAb as single agent; 4) studies that report the ORR, stratified according to the PD-L1 expression status (IHC cut-off point 1\%).

\section{Data extraction}

Two authors independently selected studies according to the aforementioned inclusion criteria. If these two authors could not reach a consensus, another author was consulted and a final decision was made by 
consensus. Information was carefully extracted by overall selected studies. The following data were collected and organized from eligible studies: first author name, journal and year of publication, study design, study treatment, baseline characteristics of patients (i.e. age, stage, PDL1 expression status), and ORR stratified according to tumor PD-L1 expression status. The proportion of patients for each outcome was calculated basing on the percentages reported in included trials, when it was not reported as absolute number. Data extraction was conducted according to the Preferred Reporting Items for Systematic Reviews and Meta-Analysis (PRISMA) guidelines [47].

\section{Statistical analysis}

Patients were stratified according to PD-L1 expression status into 2 groups: PD-L1 positive (PDL1 tumor cell staining $\geq 1 \%$ ) and PD-L1 negative. The outcome measure was ORR, defined as the percentage of patients who have a complete or partial tumor response according to World Health Organization (WHO) criteria or Response Evaluation Criteria in Solid Tumors (RECIST), calculated in PD-L1 positive over PD-L1 negative NSCLC patients. The number of events (i.e. objective responses) was extracted from each study or calculated from the percentage provided, and the proportion of patients was calculated for each group. The association between these endpoints and PD-L1 expression status was expressed as an odds ratio (OR) of PD-L1 positive over PD-L1 negative patients. Thus, an OR greater than 1 indicates that PDL1 overexpression (PD-L1 tumor cell staining $\geq 1 \%$ ) is associated with higher ORR in pre-treated NSCLC patients. A pooled-analysis of ORs was performed to calculate a pooled OR for such outcome, using a fixedeffect or random-effect, based on statistical significance of Q-test, according to Mantel-Haenszel method. The heterogeneity between trials was tested using the Cochran Q-test, with a predefined significance threshold of 0.1. Publication bias for ORR analysis were assessed using Begg's funnel plots and Egger's test. The level of significance was set at $5 \%(\mathrm{P}<0.05$ suggested a statistical significant publication bias). All statistical analyses were performed with Review Manager 5.3.5 (RevMan; version 5.3.5) and Comprehensive Meta-Analysis software (CMA; version 3.0).

\section{ACKNOWLEDGMENTS}

Dr. Chiara Drago contributed to the revision of the English language of this manuscript.

\section{CONFLICTS OF INTEREST} interests.

\section{GRANT SUPPORT}

This work was supported by the Consorzio Interuniversitario Nazionale per la Bio-Oncologia (CINBO).

\section{REFERENCES}

1. Bronte G, Rizzo S, La Paglia L, Adamo V, Siragusa S, Ficorella C, Santini D, Bazan V, Colucci G, Gebbia N and Russo A. Driver mutations and differential sensitivity to targeted therapies: a new approach to the treatment of lung adenocarcinoma. Cancer Treat Rev. 2010; 36:S21-29.

2. Bronte G, Terrasi M, Rizzo S, Sivestris N, Ficorella C, Cajozzo M, Di Gaudio F, Gulotta G, Siragusa S, Gebbia $\mathrm{N}$ and Russo A. EGFR genomic alterations in cancer: prognostic and predictive values. Front Biosci (Elite Ed). 2011; 3:879-887.

3. Passiglia F, Bronte G, Castiglia M, Listì A, Calò V, Toia F, Cicero G, Fanale D, Rizzo S, Bazan V and Russo A. Prognostic and predictive biomarkers for targeted therapy in NSCLC: for whom the bell tolls? Expert Opin Biol Ther. 2015:1-14.

4. Bronte G, Rolfo C, Giovannetti E, Cicero G, Pauwels P, Passiglia F, Castiglia M, Rizzo S, Vullo FL, Fiorentino E, Van Meerbeeck J and Russo A. Are erlotinib and gefitinib interchangeable, opposite or complementary for non-small cell lung cancer treatment? Biological, pharmacological and clinical aspects. Crit Rev Oncol Hematol. 2014; 89:300-313.

5. Bronte G, Passiglia F, Galvano A and Russo A. Antiangiogenic drugs for second-line treatment of NSCLC patients: just new pawns on the chessboard? Expert Opin Biol Ther. 2015:1-5.

6. Bronte G, Sortino G, Passiglia F, Rizzo S, Lo Vullo F, Galvano A, Bazan V, Rolfo C and Russo A. Monoclonal antibodies for the treatment of non-haematological tumours: update of an expanding scenario. Expert Opin Biol Ther. 2015; 15:45-59.

7. Vesely MD, Kershaw MH, Schreiber RD and Smyth MJ. Natural innate and adaptive immunity to cancer. Annu Rev Immunol. 2011; 29:235-271.

8. Pardoll DM. The blockade of immune checkpoints in cancer immunotherapy. Nat Rev Cancer. 2012; 12:252-264.

9. Jadus MR, Natividad J, Mai A, Ouyang Y, Lambrecht N, Szabo S, Ge L, Hoa N and Dacosta-Iyer MG. Lung cancer: a classic example of tumor escape and progression while providing opportunities for immunological intervention. Clin Dev Immunol. 2012; 2012:160724.

10. Terme M, Ullrich E, Aymeric L, Meinhardt K, Desbois M, Delahaye N, Viaud S, Ryffel B, Yagita H, Kaplanski G, Prévost-Blondel A, Kato M, Schultze JL, Tartour E, Kroemer G, Chaput N, et al. IL-18 induces PD-1dependent immunosuppression in cancer. Cancer Res. 2011; 71:5393-5399. 
11. Topalian SL, Drake CG and Pardoll DM. Targeting the PD-1/B7-H1(PD-L1) pathway to activate anti-tumor immunity. Curr Opin Immunol. 2012; 24:207-212.

12. Keir ME, Liang SC, Guleria I, Latchman YE, Qipo A, Albacker LA, Koulmanda M, Freeman GJ, Sayegh $\mathrm{MH}$ and Sharpe AH. Tissue expression of PD-L1 mediates peripheral T cell tolerance. J Exp Med. 2006; 203:883-895.

13. Freeman GJ, Long AJ, Iwai Y, Bourque K, Chernova T, Nishimura H, Fitz LJ, Malenkovich N, Okazaki T, Byrne MC, Horton HF, Fouser L, Carter L, Ling V, Bowman MR, Carreno BM, et al. Engagement of the PD-1 immunoinhibitory receptor by a novel B7 family member leads to negative regulation of lymphocyte activation. J Exp Med. 2000; 192:1027-1034.

14. Fife BT and Bluestone JA. Control of peripheral T-cell tolerance and autoimmunity via the CTLA-4 and PD-1 pathways. Immunol Rev. 2008; 224:166-182.

15. Okazaki T and Honjo T. PD-1 and PD-1 ligands: from discovery to clinical application. Int Immunol. 2007; 19:813-824.

16. Brahmer JR. Harnessing the immune system for the treatment of non-small-cell lung cancer. J Clin Oncol. 2013; 31:1021-1028.

17. Rolfo C, Sortino G, Smits E, Passiglia F, Bronte G, Castiglia M, Russo A, Santos ES, Janssens A, Pauwels P and Raez L. Immunotherapy: is a minor god yet in the pantheon of treatments for lung cancer? Expert Rev Anticancer Ther. 2014; 14:1173-1187.

18. Homet Moreno B and Ribas A. Anti-programmed cell death protein-1/ligand-1 therapy in different cancers. Br J Cancer. 2015; 112:1421-1427.

19. Gettinger SN, Horn L, Gandhi L, Spigel DR, Antonia SJ, Rizvi NA, Powderly JD, Heist RS, Carvajal RD, Jackman DM, Sequist LV, Smith DC, Leming P, Carbone DP, Pinder-Schenck MC, Topalian SL, et al. Overall Survival and Long-Term Safety of Nivolumab (Anti-Programmed Death 1 Antibody, BMS-936558, ONO-4538) in Patients With Previously Treated Advanced Non-Small-Cell Lung Cancer. J Clin Oncol. 2015; 33:2004-2012.

20. Garon EB, Rizvi NA, Hui R, Leighl N, Balmanoukian AS, Eder JP, Patnaik A, Aggarwal C, Gubens M, Horn L, Carcereny E, Ahn MJ, Felip E, Lee JS, Hellmann MD, Hamid O, et al. Pembrolizumab for the treatment of non-small-cell lung cancer. N Engl J Med. 2015; 372:2018-2028.

21. Rizvi NA, Chow LQM, Dirix LY, Gettinger SN, Gordon MS, Kabbinavar FF, Von Pawel J, Soria J-C, Chappey C, Mokatrin A, Sandler A, Waterkamp D, Spigel DR. Clinical trials of MPDL3280A (anti-PDL1) in patients (pts) with non-small cell lung cancer (NSCLC). J Clin Oncol. 2014; 32.

22. Rizvi NA, Brahmer JR, Ou SHI, Segal NH, Khleif S, Hwu W-J, Gutierrez M, Schoffski P, Hamid O, Weiss J, Lutzky J, Maio M, Nemunaitis JJ, Jaeger D, Balmanoukian AS,
Rebelatto M, et al. Safety and clinical activity of MEDI4736, an anti-programmed cell death-ligand 1 (PD-L1) antibody, in patients with non-small cell lung cancer (NSCLC). J Clin Oncol. 2015; 33.

23. Brahmer J, Reckamp KL, Baas P, Crinò L, Eberhardt WE, Poddubskaya E, Antonia S, Pluzanski A, Vokes EE, Holgado E, Waterhouse D, Ready N, Gainor J, Arén Frontera O, Havel L, Steins M, et al. Nivolumab versus Docetaxel in Advanced Squamous-Cell Non-Small-Cell Lung Cancer. N Engl J Med. 2015; 373:123-135.

24. Borghaei H, Paz-Ares L, Horn L, Spigel DR, Steins M, Ready NE, Chow LQ, Vokes EE, Felip E, Holgado E, Barlesi F, Kohlhäufl M, Arrieta O, Burgio MA,Fayette $\mathrm{J}$, Lena $\mathrm{H}$, et al. Nivolumab versus Docetaxel in Advanced Nonsquamous Non-Small-Cell Lung Cancer. N Engl J Med. 2015; 373:1627-39.

25. Topalian SL, Hodi FS, Brahmer JR, Gettinger SN, Smith DC, McDermott DF, Powderly JD, Carvajal RD, Sosman JA, Atkins MB, Leming PD, Spigel DR, Antonia SJ, Horn L, Drake CG, Pardoll DM, et al. Safety, activity, and immune correlates of anti-PD-1 antibody in cancer. N Engl J Med. 2012; 366:2443-2454.

26. Rizvi NA, Mazières J, Planchard D, Stinchcombe TE, Dy GK, Antonia SJ, Horn L, Lena H, Minenza E, Mennecier B, Otterson GA, Campos LT, Gandara DR, Levy BP, Nair $\mathrm{SG}$, Zalcman G, et al. Activity and safety of nivolumab, an anti-PD-1 immune checkpoint inhibitor, for patients with advanced, refractory squamous non-small-cell lung cancer (CheckMate 063): a phase 2, single-arm trial. Lancet Oncol. 2015; 16:257-265.

27. Spira AI, Park K, Mazières J, Vansteenkiste JF, Rittmeyer A, Ballinger M, Waterkamp D, Kowanetz M, Mokatrin A, Fehrenbacher L. Efficacy, safety and predictive biomarker results from a randomized phase II study comparing MPDL3280A vs docetaxel in 2L/3L NSCLC (POPLAR) J Clin Oncol. 2015; 33.

28. Horn L, Spigel DR, Gettinger SN, Antonia SJ, Gordon MS, Herbst RS, Sequist LV, Chappey C, Kowanetz M, Sandler A, Soria J-C. Clinical activity, safety and predictive biomarkers of the engineered antibody MPDL3280A (anti-PDL1) in non-small cell lung cancer (NSCLC): update from a phase Ia study. J Clin Oncol; 2015:33.

29. Gettinger SN, Hellmann MD, Shepherd FA, Antonia SJ, Brahmer JR, Chow LQM, Goldman JW, Juergens RA, Borghaei H, Ready N, Gerber DE, Nathan FE, Shen Y, Harbison C, Rizvi NA. First-line monotherapy with nivolumab (NIVO; anti-programmed death-1 [PD-1]) in advanced non-small cell lung cancer (NSCLC): Safety, efficacy and correlation of outcomes with PD-1 ligand (PDL1) expression. J Clin Oncol. 2015; 33.

30. Gulley JL, Spigel D, Kelly K, Chandler JC, Rajan A, Hassan R, Wong DJL, Leach J, Edenfield WJ, Wang D, Vrindavanam N, Weiss GJ, Gurtler JS, Grote HJ, von Heydebreck A, et al. Avelumab (MSB0010718C), an antiPD-L1 antibody, in advanced NSCLC patients: A phase 
$1 \mathrm{~b}$, open-label expansion trial in patients progressing after platinum-based chemotherapy. J Clin Oncol; 2015: 33.

31. Kerr KM, Tsao MS, Nicholson AG, Yatabe Y, Wistuba II, Hirsch FR; IASLC Pathology Committee. Programmed Death-Ligand 1 Immunohistochemistry in Lung Cancer: In what state is this art? J Thorac Oncol 2015; 10:985-989.

32. Sui X, Ma J, Han W, Wang X, Fang Y, Li D, Pan H and Zhang L. The anticancer immune response of anti-PD-1/ PD-L1 and the genetic determinants of response to anti-PD-1/PD-L1 antibodies in cancer patients. Oncotarget. 2015; 6:19393-19404. doi:10.18632/oncotarget.5107.

33. Tang Y, Fang W, Zhang Y, Hong S, Kang S, Yan Y, Chen N, Zhan J, He X, Qin T, Li G, Tang W, Peng P and Zhang L. The association between PD-L1 and EGFR status and the prognostic value of PD-L1 in advanced non-small cell lung cancer patients treated with EGFR-TKIs. Oncotarget. 2015; 6:14209-14219. doi:10.18632/oncotarget.3694.

34. Kazandjian D, Blumenthal GM, Zhang L, Khozin S, Thang S, Keegan P, Pazdur R. An Exploratory Responder Analysis of Best RECIST Response and Survival in Patients with Metastatic Squamous NSCLC Treated with Nivolumab. Journal of Thoracic Oncology. 2015:10. (http://journals. lww.com/jto/toc/2015/09001)

35. Wolchok JD, Hoos A, O'Day S, Weber JS, Hamid O, Lebbé C, Maio M, Binder M, Bohnsack O, Nichol G, Humphrey R and Hodi FS. Guidelines for the evaluation of immune therapy activity in solid tumors: immunerelated response criteria. Clin Cancer Res. 2009; 15:7412-7420.

36. Marti AM, Martinez P, Navarro A, Cedres S, MurtraGarrell N, Salva F, Sansano I, Romero L, Felip E, Nuciforo P. Concordance of PD-L1 expression by different immunohistochemistry (IHC) definitions and in situ hybridization (ISH) in squamous cell carcinoma (SCC) of the lung. J Clin Oncol. 2014; 32.

37. Callea M, Genega EM, Gupta M, Fay AP, Song J, Carvo I, Bhatt RS, McDermott DF, Atkins MB, Choueiri TK, Freeman GJ, Signoretti S. PD-L1 expression in primary clear cell renal cell carcinomas (ccRCCs) and their metastases. J Clin Oncol. 2014; 32:5s.

38. Kowanetz M, Sembabaoglu Y, Koeppen H, Chaft J, Rudin C, Zou W, Nickles D, Desai R, Nakamura R, Sandler A, Amler L, Hegde PS, Rizvi N, Hellmann M. Spatiotemporal Effects on Programmed Death Ligand 1
(PD-L1) Expression and Immunophenotype of Non-Small Cell Lung Cancer (NSCLC). Journal of Thoracic Oncology. 2015; 10:9 (http://journals.lww.com/jto/toc/2015/09001).

39. Taube JM, Klein A, Brahmer JR, Xu H, Pan X, Kim JH, Chen L, Pardoll DM, Topalian SL and Anders RA. Association of PD-1, PD-1 ligands, and other features of the tumor immune microenvironment with response to anti-PD-1 therapy. Clin Cancer Res. 2014; 20:5064-5074.

40. Spranger S, Bao R and Gajewski TF. Melanoma-intrinsic $\beta$-catenin signalling prevents anti-tumour immunity. Nature. 2015; 523:231-235.

41. Ji RR, Chasalow SD, Wang L, Hamid O, Schmidt H, Cogswell J, Alaparthy S, Berman D, Jure-Kunkel M, Siemers NO, Jackson JR and Shahabi V. An immune-active tumor microenvironment favors clinical response to ipilimumab. Cancer Immunol Immunother. 2012; 61:1019-1031.

42. Spranger S, Spaapen RM, Zha Y, Williams J, Meng Y, Ha TT and Gajewski TF. Up-regulation of PD-L1, IDO, and $\mathrm{T}$ (regs) in the melanoma tumor microenvironment is driven by CD8(+) T cells. Sci Transl Med. 2013; 5:200ra116.

43. Tumeh PC, Harview CL, Yearley JH, Shintaku IP, Taylor EJ, Robert L, Chmielowski B, Spasic M, Henry G, Ciobanu V, West AN, Carmona M, Kivork C, Seja E, Cherry G, Gutierrez AJ, et al. PD-1 blockade induces responses by inhibiting adaptive immune resistance. Nature. 2014; 515:568-571.

44. Herbst RS, Soria JC, Kowanetz M, Fine GD, Hamid O, Gordon MS, Sosman JA, McDermott DF, Powderly JD, Gettinger SN, Kohrt HE, Horn L, Lawrence DP, Rost S, Leabman M, Xiao Y, et al. Predictive correlates of response to the anti-PD-L1 antibody MPDL3280A in cancer patients. Nature. 2014; 515:563-567.

45. Teng MW, Ngiow SF, Ribas A and Smyth MJ. Classifying Cancers Based on T-cell Infiltration and PD-L1. Cancer Res. 2015; 75:2139-2145.

46. Rizvi NA, Hellmann MD, Snyder A, Kvistborg P, Makarov V, Havel JJ, Lee W, Yuan J, Wong P, Ho TS, Miller ML, Rekhtman N, Moreira AL, Ibrahim F, Bruggeman C, Gasmi B, et al. Cancer immunology. Mutational landscape determines sensitivity to PD-1 blockade in non-small cell lung cancer. Science. 2015; 348:124-128.

47. Moher D, Liberati A, Tetzlaff J, Altman DG and Group P. Preferred reporting items for systematic reviews and meta-analyses: the PRISMA statement. Int J Surg. 2010; 8:336-341. 